\title{
Quality in Mobile Payment Service in India
}

\author{
Bhartendra Pratap Singh*, Purva Grover, Arpan Kumar Kar \\ Department of Management Studies, Indian Institute of Technology (Delhi), New Delhi, India \\ *singhbp.dms.iitdegmail.com
}

\begin{abstract}
This study seeks to determine the dimensions of quality from the perspective of "voice of the consumer". It uses the Total Interpretive Structural Modelling (TISM) with construct of Usefulness, Ease of Use, Security \&Trust, Visual Appeal, Complementary Relationship and Customer Service. The general theoretical framework of the Theory of Reasoned Action (TRA), Technology Acceptance Model (TAM), SERVQUAL, WebQual and Quality Function Deployment have been used to develop a questionnaire for Mobile Payment Service (MPS) quality. Individual's response to questions about the quality in MPS, they are using were collected and analysed with TISM. Though, the analysis confirms with the classical theory of TAM (i.e. Usefulness and Ease of Use), additionally the results also shows the consumers perceived concern about trust and security. There is also existence of significant relationship observed between demographics of the respondents and variables measured. The study intended to analyse the service quality in MPS in light of extant research on Technology Acceptance and Service Quality via construct of behavioural interaction to use and actual usage.
\end{abstract}

Keywords: Mobile payments; WebQual, Quality Function Deployment (QFD), Total Interpretational Structural Model (TISM)

\section{$1 \quad$ Introduction}

Nowadays the wireless feature of mobile phones is continuously inspiring creation of value added services and functionalities which surpass telephony needs [8]. Due to the exponential growth in the subscribers and wider coverage in India, mobile has offered an option of delivering banking and payment services. A Mobile Payments Service (MPS) is a usage of mobile device supported with wireless and communication technology for payment bills, goods and services [3]. Further, demonetization of Rs. 500 and 1,000 currency tenders on November 08, 2016 by Government of India and highest emphasis on cashless economy has put digital payment on forefront. Among other digital payment modes, MPS has an increasing importance and development in essential mode of low value and high frequency money transactions. Therefore, field of MPS is already witnessing the increasing competition in India, post demonetisation and only providing service will not be adequate to gain competitive advantage. The mobile payment transaction volume is likely to register a compound growth rate of $90 \%$ to reach 15 billion by year 2022 (Mint, November 10, 2016).

adfa, p. 1, 2011.

(C) Springer-Verlag Berlin Heidelberg 2011 
This study determines the dimension of quality in MPS and their effect on customer satisfaction. The study will determine the dimensions of quality with respect to the perspective of the customer. Service quality in MPS is determined by TISM, on the basis of survey undertaken. On the integrated theoretical framework of SERVQUAL [31], WebQual [5, 13, 30], QFD; the current study undertakes an empirical assessment using the research model in context of the MPS.

\section{$2 \quad$ Literature Review}

MPS is a mobile phone based application, provided with the utilities of a bank credit card/debit card and other features of financial transactions capable to replace person's wallet [20]. As per [19], in mobile payment at least a payer engages mobile device to carry out payment transaction. The rapid mobile technology evolution followed by mobile phone users expanding base, it has been identified that the commercial industry of mobile applications is having a high growth potential [2]. MPS can support both $\mathrm{C} 2 \mathrm{C}$ and $\mathrm{C} 2 \mathrm{~B}$ transactions on all type of Point-of-Sales (PoS). Evaluating the quality in MPS can be approached from three major methods - machine, expert analysis and customer evaluation. Since the customer point of view gets ignored in machine or expert approach, asking customer is desirable $[12,13]$.

\subsection{Service Quality}

The quality of any service from the view point of consumer is considered as judgment of overall excellence or superiority [6, 29]. According to SERVQUAL scale [17] service quality is a gap between perceived service expectation and perceived service performance. Therefore, service quality may be explained in a form of a simple equation as:

$$
\mathrm{SQ}=\mathrm{P}-\mathrm{E}
$$

Where: $\mathrm{SQ}=$ service quality, $\mathrm{P}=$ perceived delivery of the service by the individual, $\mathrm{E}=$ expected delivery of the service by the individual

\subsection{Website Service Quality}

Consumers' perception of quality and their usage behavior [1] towards MPS can better explained using Unified Theory of Acceptance and Use of Technology (UTAUT) model [23]. In current study paper following aspects: perceived usefulness, perceived ease of use, perceived security\& Trust, self-efficacy and social influence. Further, this paper examines three moderating variables (age, earning, and location type) that have varying influences on the primary constructs. MPS application is founded on the contention of internet service or MIS, therefore theories related to WebQual [12] are applicable. In a mobile based service, the employment of software, hardware, networking, storage, display, process or transfer are information system element [26]. 


\subsection{Additional Aspects of Mobile Payment Service}

Ubiquity. The most cited example of network effect is the telecommunications, which is the leveraging on mobile phones platform effect. Therefore, success of MPS is also depends upon the management of ubiquity at the similar levels as the mobile phone. Ubiquity is the reason behind persistence of high expectation from MPS in future [18]. There are two dimensions of ubiquity: ubiquity of availability and ubiquity of use.

Security and Trust. Security is the subjective issue and depends on user specific perception affected by cultural and socio-economic parameters. In context of payment, brand name has a better chance to gain trust due to familiarity gained through frequent exposure and has high potential to motivate trust [27].Customer loyalty and satisfaction towards mobile modes positively influenced by trust factor [11].

\subsection{Total Interpretive Structural Model (TISM)}

Interpretive Structural Model (ISM) [25] can effectively derive the interrelation among elements and their level of association. ISM has been used to articulate disjointed and ambiguous rational system models to visible, well-defined models [22]. In the ISM diagraph can be interpreted at two levels i.e. nodes and links. Though ISM defines nodes in terms of the elements representing it, however the interpretation of link direction is inadequate. The links simply indicate the directional relationship between nodes but, it does neither captured nor represented the causal thinking behind the interrelation of paired comparison. Therefore, there is a requirement to interpret the casual thinking behind the paired interrelationship. Total interpretive structural modelling (TISM) [22, 28] by using the tool of Interpretive Matrix [21] evolves methodology and framework for conceptualizing scantily articulated mental models. The TISM model in present study is developed on the basis of the work done by researchers on WebQual $[4,5,12]$ and mobile wallet [20]. On the basis of literature review, a questionnaire was prepared to validate the assumptions. The TISM is used to develop a hierarchical structure of the set variables, which helps transform poorly articulated mental models into systematic form.

\section{$3 \quad$ Study Design}

The study design largely follows the MPS survey design used by method used by [12] and [4]. The survey method adopted was through a questionnaire consisting of 46 questions. Prior commencement of full-fledged survey, the questionnaire was tested by administering a pilot survey undertaken to examine test-retest reliability and construct reliability before conducting the fieldwork. At the end by minimizing the uncertainty in syntax and semantics, the final survey through a questionnaire consisting of 24 questions (Exhibit 1) was administered online as well as offline in January and February 2017. By the end of survey total 266 responses were captured. Of the submitted responses 12 were omitted because of incomplete answers, balance of which 254 were complete responses and considered for analysis. 
In order to improve validity and generalizability, respondents were selected from various class of the cities i.e. Class A, B and C (classification by Government of India for the purpose of House Rent Allowance on the basis of cost of living). However, it was observed during analysis that the sample is unbalanced in in terms of brand of MPS subscription (fig 1). It has been observed the subscription of PayTm brand within the sample is as high as $94 \%$ (239 responses). The subscription of all other brands (i.e. ICICI, Airtel,BHIM, iMobile and MobiKwik) was only 15 (6\%) in the sample of 254 good responses. So, it was decided during the study that the quality evaluation in Mobile Payment Service will be undertaken only for PayTm brand with a sample size of 239.

The final sample demographics presented in Table 1 is rather unbalanced with respect to city class, age and income group. This may have resulted due to proximity of survey efforts concentration to National Capital Region (NCR). Additionally, considering the nature of mobile payment, this unbalance is understandable because a large number of smart phone users are young and from middle income group.

Table 1. Characteristics of Respondents (total $=239$ )

\begin{tabular}{|l|l|l|}
\hline City Class & Number & \% \\
\hline Class A & 123 & 51 \\
\hline Class B & 75 & 31 \\
\hline Class C & 41 & 17 \\
\hline Age (Years) & Number & \% \\
\hline Under 25 & 62 & 26 \\
\hline $25-35$ & 130 & 54 \\
\hline $35-45$ & 28 & 12 \\
\hline Above 45 & 19 & 8 \\
\hline Income Group (INR ,000) & Number & \% \\
\hline Less Than 25 & 89 & 37 \\
\hline $25-75$ & 101 & 42 \\
\hline $75-150$ & 32 & 13 \\
\hline More Than 150 & 17 & 7 \\
\hline
\end{tabular}

\subsection{Data Analysis}

The respondents indicated their agreement or disagreement with a set of statements, using a 5-point Likert-type scale (ranging from "strongly agree" to "strongly disagree"). Since, option 1 was given to "strongly agree" and option 5 to "strongly disagree" on 5-point Likert-type scale, the points closer to the center are indicative of agreement and points on periphery are indicative of disagreement. The questions were further grouped to form elements, which can be co-related to the attributes the MPS quality (Exhibit 2). 


\section{Development of Total Interpretive Structural Model}

For the development of TISM model, help of past studies [14, 15] has been taken to identify the elements and moderators. The pioneer work of TISM [22] is used to build up a hierarchical structure of the set of variables of interest.

\subsection{Elements and Contextual relationship}

Perceived Usefulness and Perceived Ease of Use. Above are two distinct but interrelated beliefs as per TAM. Among these two variables, perceived usefulness have the stronger influence [7]. Which is the degree to which a consumer believes that the service will satisfy his/ her need. However, perceived ease of use refers believe of the consumer to use the service will be effortless [24].

E1: Perceived usefulness has a positive effect on attitude toward the MPS.

E2: Perceived ease of use has a positive effect on attitude toward the MPS.

Aesthetics. This dimension concerns with the visual characteristics of the of the application design that attracts the user's attentions and encourages them to reuse the payment service. This dimension is covered by most of the IS studies due to its importance. All the mobile application companies give a great emphasis on this aspect. The combined appeal of the application will make the user happy, pleasant, enjoyable and cheerful [4].

E3: Aesthetics is positively related to intension to use MPS.

Security \& Trust. The degree to which a customer believes that using MPS will be secure [20]. Perception of lack of security in digital payments is the most common reason for a refusal to use. Trust is the predecessor variable to the intention to use a MPS. Therefore, it is vital for mobile payment service provider to build trust through website and risk assessments.

E4: Security \& Trust has a positive effect on the intention to use MPS.

Ubiquity. MPS application fulfills the customer need of accessing information and service for payment at anytime from anywhere [18].

E5: Ubiquity of MPS has a positive effect on intension to use.

Complimentary Relationship. How the usage of MPS application is better than other modes of transactions and better than other applications? Des it also allows all or most necessary payment transactions to be completed? These are important aspects. E6: Complementary Relationship positively related to intention to use MPS.

Customer Service. The customer response to feedbacks, inquiries and comments is an essential aspect of MPS quality [10, 16]. This is also a deciding factor for customer loyalty.

E7: Quality of Customer Service in MPS affects the customer's intention to use. 
Demographic Factors. These are the variables that represent association between other variables. The direction and strength of various relationships is shaped by the crucial role of age, gender, income etc. As per TAM research, age is an important parameter of market segmentation. Age also moderates technology adoption-related relationships [23]. Classification of city of MPS user is considered in current study as a vital personal characteristic. The impact of class of the city on adoption behavior has been a point of interest. Class ' $\mathrm{C}$ ' city MPS customers is found to be strongly influenced by their perception of security.

E8: Age group of the user affects the intention to use MPS.

E9: Income group of the user has positive effect on attitude towards the MPS.

E10: The class of city of residence and usage of customer affects attitude towards MPS.

\subsection{Defining Contextual Relationship}

All the elements that affects the customer attitude towards MPS are subject to paired comparison to evolve the interpretive logic - knowledge base, which is converted into reachability matrix. The contextual relationship identified was 'Attribute A will influence / enhance attribute B'. Since, there was 10 attributes, the total number of rows in the knowledge base was $90\left(=10^{* 9}\right)$. The relationship in the knowledge base were designed with the help of Cronbach Alfa and established relationship in previous studies. The value of Cronbach Alfa above 0.7 was considered Y, otherwise $\mathrm{N}$ was marked in pairwise comparison. It has been observed that the high value of Alfa from survey in current study is also supported by previous research in case of most of the pairs. The final Knowledge base was developed for all the paired relationships.

\subsection{Reachability Matrix}

Further, transitivity concept is introduced to develop final reachability matrix so that some of the cells of initial reachability matrix are filled by inference [9]. The concept of transitivity can be explained as follows:-

If, $\left(\left(\right.\right.$ Element $_{i} \rightarrow$ Element $\left._{j}\right)$ and $\left(\right.$ Element $_{j} \rightarrow$ Element $\left.\left._{k}\right)\right)$

then: (Element $t_{i} \rightarrow$ Element $\left._{k}\right)$

Transitivity is the ground assumption in ISM and be always used in modeling approach [21]. Transitivity also strengthens the consistency of the model. Final reachability matrix with transitive links is shown in Table 2 . The antecedents and reachability of each element of enablers are drawn from the final reachability matrix. Reachability set consists of a group of enablers itself and other enablers, which may help in realizing the enabler. On the other hand antecedents set consists of a group of enablers itself and other enablers, which may help achieving it. Further, elements present in both reachability set as well as antecedent set are positioned as intersection set. The elements having same reachability set and interaction set are positioned at top spot. The elements already secured position in levels are removed to recognize next level and the cycle is repeated until all elements are placed hierarchical levels. These levels are utilized for formation diagraph. The final level matrix is shown at Table 3. 
Table 2. Final reachability matrix with transitivity (Transitive relation are shown with *)

\begin{tabular}{|c|c|c|c|c|c|c|c|c|c|c|}
\hline Elements & E1 & E2 & E3 & E4 & E5 & E6 & E7 & E8 & E9 & E10 \\
\hline E1 & 1 & 0 & 0 & 0 & 0 & 0 & 0 & 0 & 0 & 0 \\
\hline E2 & 1 & 1 & 0 & 0 & 0 & 1 & 0 & 0 & 0 & 0 \\
\hline E3 & 1 & 1 & 1 & 0 & 0 & $1^{*}$ & 0 & 0 & 0 & 0 \\
\hline E4 & $1^{*}$ & 0 & 0 & 1 & 0 & 1 & 1 & 0 & 0 & 0 \\
\hline E5 & $1^{*}$ & 1 & 0 & 0 & 1 & $1^{*}$ & 0 & 0 & 0 & 0 \\
\hline E6 & 1 & 0 & 0 & 0 & 0 & 1 & 0 & 0 & 0 & 0 \\
\hline E7 & 1 & 0 & 0 & 0 & 0 & 1 & 1 & 0 & 0 & 0 \\
\hline E8 & 1 & 0 & 0 & 1 & 0 & $1^{*}$ & $1^{*}$ & 1 & 0 & 0 \\
\hline E9 & 1 & $1^{*}$ & 0 & 0 & 1 & $1^{*}$ & 1 & 0 & 1 & 0 \\
\hline E10 & 1 & $1^{*}$ & 0 & 1 & 1 & $1^{*}$ & $1^{*}$ & 0 & 0 & 1 \\
\hline
\end{tabular}

Table 3. Level Matrix

\begin{tabular}{|c|c|c|}
\hline $\begin{array}{l}\text { Element } \\
\text { Code }\end{array}$ & Enablers & Level \\
\hline E1 & $\begin{array}{l}\text { Perceived usefulness has a positive effect on attitude toward the } \\
\text { MPS. }\end{array}$ & I \\
\hline $\mathbf{E 2}$ & $\begin{array}{l}\text { Perceived ease of use has a positive effect on attitude toward the } \\
\text { MPS. }\end{array}$ & III \\
\hline $\mathbf{E 3}$ & Aesthetics is positively related to intension to use MPS. & IV \\
\hline $\mathbf{E 4}$ & $\begin{array}{l}\text { Security \& Trust has a positive effect on the intention to use } \\
\text { MPS. }\end{array}$ & IV \\
\hline $\mathbf{E 5}$ & Ubiquity of MPS has a positive effect on intension to use. & IV \\
\hline E6 & $\begin{array}{l}\text { Complementary Relationship positively related to intention to } \\
\text { use MPS. }\end{array}$ & II \\
\hline E7 & $\begin{array}{l}\text { Quality of Customer Service in MPS affects the customer's in- } \\
\text { tention to use. }\end{array}$ & III \\
\hline E8 & Age group of the user affects the intention to use MPS. & $\mathrm{V}$ \\
\hline E9 & $\begin{array}{l}\text { Income group of the user has positive effect on attitude towards } \\
\text { the MPS. }\end{array}$ & $\mathrm{V}$ \\
\hline E10 & $\begin{array}{l}\text { The class of city of residence and usage of customer affects at- } \\
\text { titude towards MPS. }\end{array}$ & $\mathrm{V}$ \\
\hline
\end{tabular}

\subsection{Developing Diagraph}

The meaning of diagraph is directed graph, which illustrates the relationship between the elements of enablers [9]. The relationship between element $i$ to $j$ can be represented with an arrow for $i$ to $j$, which signifies element $i$ influence/ enhance element $j$. The diagraph with significant transition links for current study is shown at fig 1. A binary interaction matrix is developed from the digraph. 


\subsection{Total Interpretive Structure Model}

Fig. 1 depicts the hierarchical structure of TISM showing driving force behind users' perception of quality in Mobile Payment Service by PayTm and causal relationship towards reusability. Demographic factors have a direct influence on users' perceived trust. Towards end all the enablers are influencing and also having impact on the perception of usefulness.

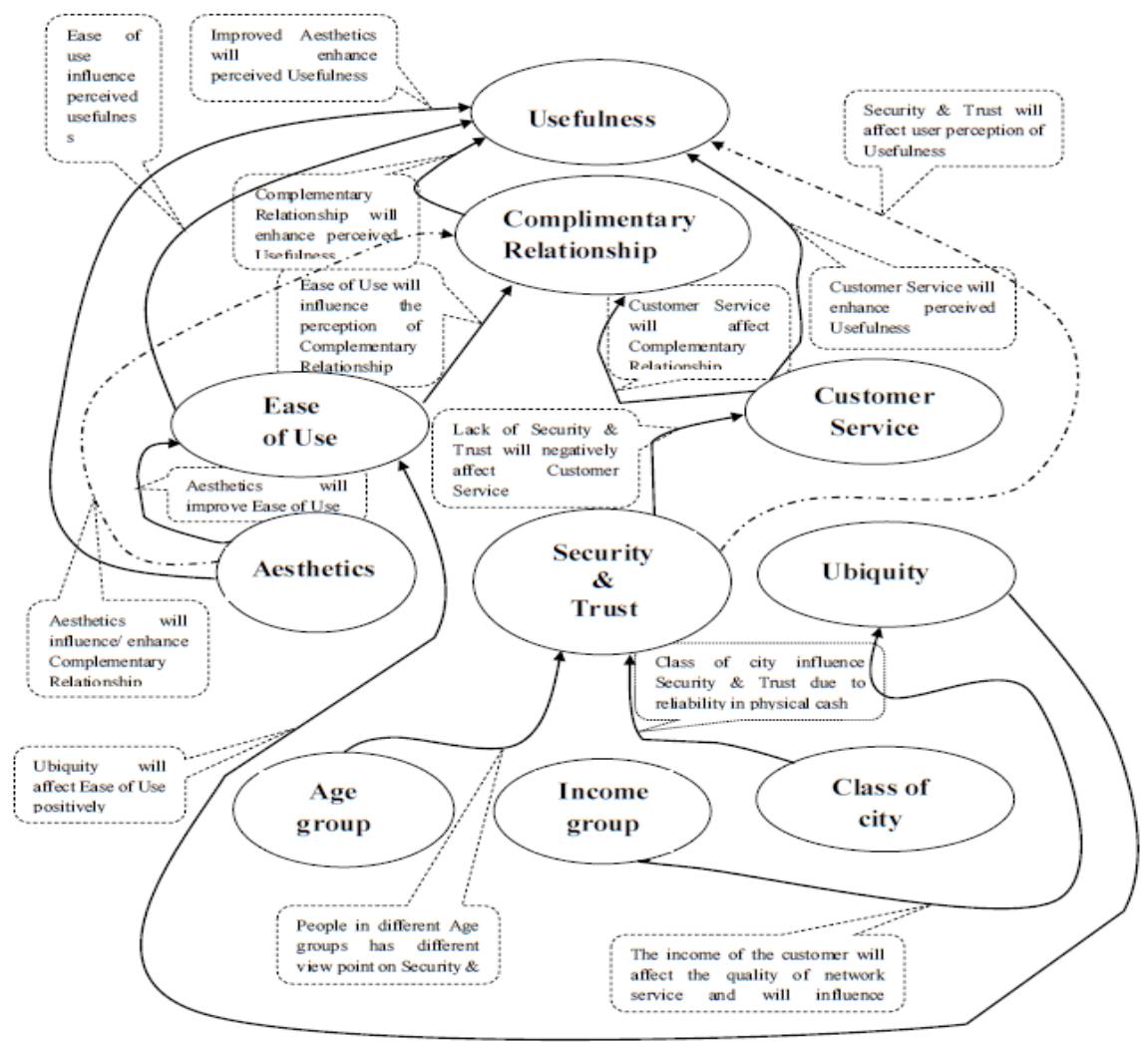

Fig. 1. Solid arrows are direct links and dotted arrows are significant Transitive Links

\section{Conclusion}

There is a widespread acceptance of mobile payment service, specifically among the young population. However, the concern of security, lack of trust, awareness and infrastructure is precluding percolation of the service to the masses. Further, the features internal to the service providers, like aesthetics, customer service and complimentary relationship will influence the perception of usefulness by the customer. The perceived usefulness by the customer is also the indicator of attitude to reuse. Therefore, the 
present study provides prescriptive advice concerning, how a service provider of MPS can improve the offering, which was not true in the case of WebQual and WebQual/M. Given that 'Usefulness' was most highly ranked dimension of the quality in MPS and has a considerable implications for the perception of quality, the same can be influenced by factors like trust and customer relationship.

\section{REFERENCES}

1. Aizen, I., Fishbein, M .: Understanding attitudes and predicting social behaviour. Englewood Cliffs, NJ: Prentice-Hall (1980).

2. Au, Y. A., Kauffman, R. J.: The economics of mobile payments: Understanding stakeholder issues for an emerging financial technology application. Electronic Commerce Research and Applications, 7(2), 141-164 (2007).

3. Balasubramanian, S., Peterson, R.A. Janvenpaa, S.L.: Exploring the implications of m-commerce for markets and marketing. Journal of the Academy of Marketing Science, 30 (4), pp.348 361 (2002).

4. Barnes, S.J., Vidgen, R.: WebQual: An Exploration of Web-site Quality. International Journal of Electronic Commerce, 6, 1 (2001), 11-30 (2001).

5. Barnes, S. J., Vidgen R.: Evaluating WAP News Sites: The WEBQUAL/ M Approach. The 9th European Conference on Information Systems, 17 (2001).

6. Cronin, J. J., Taylor, S. A.: Measuring service quality: a re-examination and extension. Journal of Marketing, 56(3), 55-68 (1992).

7. Davis, F. Perceived usefulness, perceived ease of use, and user acceptance of information technology. MIS Quarterly, 13(3), 319-340 (1989).

8. Dahlberg, T., Mallat, N., Ondrus, J. and Zmijewska, A.: Past, present and future of mobile payments research: A literature review. Electronic Commerce Research and Applications 7(2), 165-181 (2008).

9. Jayalakshmi, B., Pramod, V. R.: Total Interpretive Structural Modelling (TISM) of the Enablers of a Flexible Control System for Industry. Global Journal of Flexible Systems Management 16(1), 63-85 (2015).

10. Kreyer, N.; Pousttchi, K.; Turowski, K.: Standardized Payment Procedures as Key Enabling Factor for Mobile Commerce. E-Commerce and Web Technologies. ECWeb 2002. Aix-en-Provence 2002, pp. 400-409 (2002).

11. Lin, H.-H., Wang, Y.-S.: An examination of the determinants of customer loyalty in mobile commerce contexts.Information \& Management 43 (3), 271-282 (2006).

12. Loiacono, E. T., Watson, R. T., Goodhue, D. L.: WebQual: A measure of website quality. Marketing theory and applications, 13(3), 432-438 (2002).

13. Loiacono, E., Chen, D., \& Goodhue, D.: WebQual TM revisited: predicting the intent to reuse a Web site. AMCIS 2002 Proceedings, 46 (2002).

14. Lu, Y., Zhang, L., Wang, B.: A multidimensional and hierarchical model of mobile service quality, Electronic Commerce Research and Applications, 8(5), 228-240 (2009).

15. Mallat, N.: Exploring consumer adoption of mobile payments - A qualitative study. Journal of Strategic Information Systems 16 (4), 413-432, (2007). 
16. Ozer, A. Argan, M.T. Argan, M. (2013). The effect of mobile service quality dimensions on customer satisfaction. Procedia - Social and Behavioural Sciences 99, $428-438$ (2013).

17. Parasuraman, A., Zeithaml, V. A., Berry, L. L.: SERVQUAL: a multiple-item scale for measuring consumer perceptions of service quality, Journal of Retailing, 64(1), 12-40 (1988).

18. Pousttchi, K.; Selk, B.; Turowski, K.: Enabling mobile commerce through mass customization. In: Proceedings of the EIS 2002 Workshop on Information Systems for Mass Customization, Malaga 2002, 1-6, (2002).

19. Pousttchi, K.: Conditions for Acceptance and Usage of Mobile Payment Procedures. In: Giaglis, G. M.; Werthner, H.; Tschammer, V.; Foeschl. K.: mBusiness 2003 - The Second International Conference on Mobile Business. Vienna, 2003, 201-210 (2003).

20. Shin, Dong-Hee.: Towards an understanding of the consumer acceptance of mobile wallet. Computers in Human Behaviour 25 (6) 1343-1354 (2009).

21. Sushil.: Interpretive Matrix: A Tool to aid Interpretation of Management and Social Research. Global Journal of Flexible Systems Management 6(2), 27-30 (2005).

22. Sushil.: Interpreting the Interpretive Structural Model, Global Journal of Flexible Systems Management, 13(2), 87-106 (2012).

23. Venkatesh, V., Morris, M., Davis, G. B., Davis, F. D.: User acceptance of information technology: Toward a unified view. MIS Quarterly, 3, 425-478 (2003).

24. Viehland, D., Leong, R.: Acceptance and use of mobile payments. In 18th Australasian conference on information systems acceptance and use of Mpayments, 16, 665- 671 (2007).

25. Warfield, J. N.: Intent Structures. IEEE Transactions: System, Man and Cybernetics, SMC-3(2), 133-140 (1973).

26. Wolfinbarger, M., Gilly, M. C.: EtailQ: Dimensionalizing, Measuringand Predicting Etail Quality. Journal of Retailing, 79, 183-198 (2003).

27. Wu, J.H., Wang, S.C.: What drives mobile commerce? An empirical evaluation of the revised technology acceptance model. Information \& Management 42(5) 719729 (2005).

28. Yadav, M., Rangnekar, S., Bamel, U.: Workplace Flexibility Dimensions as Enablers of Organizational Citizenship Behaviour. Global Journal of Flexible Systems Management 17(1), 41-56 (2016).

29. Zeithaml, V.A.: Defining and Relating Prices, Perceived Quality and Perceived Value.Marketing Science Institute, Cambridge, MA, (1987).

30. Anand, O., Mittal, A...Kar, A.K.: Evaluating travel websites using WebQual: A group decision support approach. Advances in Intelligent and Soft Computing, Vol. 321, 151-160 (2015).

31. Kalelkar, G. R., Kumbhare, G., Mehta, V., Kar, A. K.: Evaluating E-Commerce Portals from the Perspective of the End User-A Group Decision Support Approach. In SIRS, 107-117 (2014). 


\section{Exhibit 1: Questionnaire}

1. The OS on my mobile is -

2. Mobile Payment App I am using frequently is -

3. The App is always available for payment.

4. The App loads quickly.

5. Learning to operate the App is easy for me.

6. I find the App easy to use.

7. The display pages within the App are easy to read.

8. When I use the App there is very little waiting time between my actions and the response.

9. The App design is visually pleasing and innovative.

10. The App's impression (image) matches that of the company.

11. The App has interactive features, which help me accomplish my task.

12. All my payments can be completed via the App.

13. It has useful links to other Apps and sites.

14. It is easier to use the App to complete my payments than it is to conventional means.

15. The payment through this Mobile Payment App is more convenient than using internet banking.

16. I trust the App to keep my personal information safe.

17. I consider mode of payment through Mobile App safer than cash/ card payment.

18. I use this Mobile App because it is better than other popular Mobile Payment Apps.

19. The App makes easy to contact the service provider/ give feedback.

20. The App service provider quickly resolves the payment transaction problems/ errors.

21. I also use below Mobile Payment Apps in addition to mentioned above at serial 2-

22. Please select your age group (years).

23. Please select your monthly income group (INR, 000).

24 . Which city you are residing in?

Exhibit2: Table 4. Mobile Payment Service Quality Items by Construct

\begin{tabular}{|l|}
\hline USEFULNESS: \\
\hline 4. The App loads quickly. \\
\hline $\begin{array}{l}\text { 8. When I use the App there is very little waiting time between my actions and the } \\
\text { response. }\end{array}$ \\
\hline 11. The App has interactive features, which help me accomplish my task. \\
\hline 12. All my payments can be completed via the App. \\
\hline 13. It has useful links to other Apps and sites. \\
\hline EASE OF USE: \\
\hline 5. Learning to operate the App is easy for me. \\
\hline 6. I find the App easy to use. \\
\hline 7. The display pages within the App are easy to read. \\
\hline AESTHETICS: \\
\hline 9. The App design is visually pleasing and innovative. \\
\hline SECURITY \& TRUST: \\
\hline 10. The App's impression (image) matches that of the company. \\
\hline 16. I trust the App to keep my personal information safe. \\
\hline
\end{tabular}


17. I consider mode of payment through Mobile App safer than cash/ card payment. UBIQUITY:

3. The App is always available for payment.

COMPLEMENTARY RELATIONSHIP:

14. It is easier to use the App to complete my payments than it is to conventional means.

15. The payment through this Mobile Payment App is more convenient than using internet banking.

18. I use this Mobile App because it is better than other popular Mobile Payment Apps.

CUSTOMER SERVICE

19. The App makes easy to contact the service provider/ give feedback.

20. The App service provider quickly resolves the payment transaction problems/ errors. 